\title{
HISTORIA DE VIDA DE UNA COLECCIÓN. EL CASO DEL MUSEO ARQUEOLÓGICO DE CHASICÓ, PARTIDO DE TORNQUIST (PROVINCIA DE BUENOS AIRES)
}

\author{
Oliva, Camila ${ }^{1}$ \\ Recibido: 6 de diciembre de 2018. Aceptado: 21 de abril de 2019
}

\begin{abstract}
Resumen
Algunas de las colecciones arqueológicas de importantes museos de la República Argentina han sido investigadas extensamente por la comunidad científica, principalmente en relación a su valoración material como evidencia de la ocupación pretérita de grupos humanos. Sin embargo, los estudios de este tipo de colecciones en los museos locales de la Provincia de Buenos Aires han sido escasamente desarrollados. Las colecciones pueden ser abordadas como archivos históricos, dado que contienen información de la contextualización historiográfica del momento de su conformación; en este sentido, no es posible considerar a la colección sin la figura del sujeto que la conformó y su capacidad de agencia (i.e. coleccionistas, aficionados, arqueólogos, historiadores, entre otros). El objetivo principal de este artículo es analizar los relatos que dan cuenta del proceso de creación de las colecciones del Museo Arqueológico de Chasicó, ubicado en la Estancia Don Natalio, partido de Tornquist, provincia de Buenos Aires. Cabe destacar que se trata de una institución declarada Sitio Histórico Municipal desde el año 2006, y cuenta con un importante número de piezas paleontológicas y arqueológicas prehispánicas e históricas correspondientes a los grupos humanos que habitaron el sector sur del Área Ecotonal Húmedo Seca Pampeana. Bajo este marco, se propone abordar metodológicamente el registro de la memoria oral de la Licenciada Nora Cinquini, tutora de las colecciones que alberga el museo. De esta manera, se entiende a la memoria como una forma de expresión de identidad, la cual permite considerar a los procesos de construcción identitarios de una comunidad y su vínculo con el pasado. El presente trabajo busca indagar la utilidad, el valor académico y los aportes generados por los estudios historiográficos -en cuanto al origen de las colecciones arqueológicas museísticas- para la comprensión de procesos identitarios que emergen de este tipo de institución.
\end{abstract}

Palabras clave: Colección arqueológica, Museo, Memoria oral, Patrimonio.

\begin{abstract}
Some of the archaeological collections of important museums of the Argentine Republic have been extensively researched by the scientific community, mainly in relation to their material valuation as evidence of the past occupation of human groups. However, the studies of this type of collections in the local museums of the Buenos Aires province have been scarcely developed. The collections can be approached as historical archives, because their information on the historiographic contextualization at the moment of their conformation; in this sense, it is not possible to consider the collection without the figure of the subject that shaped it and his agency capacity (i.e. collectors, hobbyists, archaeologists, historians, among others). The main objective of this paper is to analyze the stories about the process of creating the collections of the Archaeological Museum of Chasico, located in the Estancia Don Natalio, Tornquist district, province of Buenos Aires. It should be noted that this institution has been
\end{abstract}

1 Laboratorio de Análisis Cerámicos, Facultad de Ciencias Naturales y Museo, Universidad Nacional de La Plata; calle 64 entre 119 y 120, La Plata; Centro de Estudios Arqueológicos Regionales, Facultad de Humanidades y Artes, Universidad Nacional de Rosario.

Email: coliva@fcnym.unlp.edu.ar 
declared a municipal historical site since 2006, and has an important number of pre-Hispanic and historical paleontological and archaeological pieces corresponding to the human groups that inhabited the southern sector of the Area Ecotonal Húmedo Seca Pampeana. Under this framework, we record the oral memory of the graduate Nora Cinquini, tutor of the the museum'collections as a method. In this way, memory is understood as a form of expression of identity, which allows to consider the construction processes that identify a community and its link with the past. The present work seeks to investigate the usefulness, the academic value and the contributions generated by the historiographic studies in order to know the origin of the museum archaeological collections - and to understand the identity processes that emerge from this type of institution.

Key words: Archaeological collection, Museum, Oral memory, Heritage.

\section{Introducción}

Las colecciones arqueológicas presentes en instituciones museísticas en el interior de la provincia de Buenos Aires se han investigado de manera parcial, por parte de la comunidad científica. No es así el caso de las colecciones de los grandes museos históricos antropológicos y de ciencias naturales: i.e. Museo de Ciencias Naturales de la Plata, Museo Bernardino Rivadavia, Museo Enográfico Ambrosetti, entre otros (Scheinsohn et al 2011). El foco de investigación ha sido puesto principalmente en los grandes hallazgos, las colecciones de magnánimos investigadores pioneros en los estudios de los primeros pobladores en el área. Tal es el caso del estudio de las colecciones de los hermanos Carlos y Florentino Ameghino (Scheinsohn et al. 2011; Solomita Banfi 2015), de Alfredo Castellanos (Solomita Banfi 2006, 2015), de Francisco Pascasio Moreno (Farro 2009), y de Luis María Torres (Buc y Coronel 2013), entre otros investigadores. Sin embargo, el presente trabajo se focaliza en aquellos "anónimos" coleccionistas y estudiosos de la historia de museos ubicados en pequeñas localidades del interior bonaerense, que tal vez por las características geográficas de emplazamiento de las instituciones, han ocupado un lugar periférico en las in- vestigaciones académicas.

La escritura de este trabajo, se vincula con el siguiente interrogante planteado: ¿son las colecciones de objetos museables y patrimoniables las que dieron lugar a la formación de instituciones que las contienen y preservan -museos-; o, a la inversa, son los objetos que ingresan en los museos los que se constituyen como colecciones y adquieren un carácter patrimonial? Esta cuestión ha sido abordada de manera parcial en relación a estudios que indagaron el lugar que las colecciones ocupan en la constitución de museos. Tal es el caso de numerosos emprendimientos santafesinos que surgieron a partir de la voluntad de personas aficionadas a los temas arqueológicos o a fundaciones (Ottalagano 2008) y de museos municipales de la provincia de Buenos Aires, los cuales durante la década de 1950 se constituyeron como instituciones museísticas a partir de la donación de colecciones privadas cedidas al municipio (Pupio 2005). Asimismo, puede mencionarse el origen impuesto de exhibiciones museísticas privadas en la provincia de San Juan, a partir de la implementación del marco normativo legal nacional (Biasatti 2012). Por otra parte, se ha investigado extensamente el rol que han desarrollado las colecciones arqueológicas en museos de ciencias naturales (Solomita Banfi 2006, 
2015; Scheinsohn et al. 2011; entre otros). Sin embargo, el análisis historiográfico de las colecciones (Farro 2009), focalizadas en los actores que las conformaron, cómo se relacionaron estos sujetos (académicos y no académicos) con los bienes arqueológicos, por qué decidieron crear una colección, con qué fines, qué relatos acompañaron a las colecciones, entre otros tópicos han sido escasamente considerados. Éstas, continúan siendo preguntas cuyas respuestas se encuentran poco desarrolladas para el caso de los museos del interior bonaerense. En esta oportunidad, se parte de la premisa de que las colecciones pueden ser abordadas como archivos históricos, dado que contienen información de la contextualización historiográfica del momento de su conformación. En este sentido, se sostiene que no es posible considerar a la colección sin la figura del sujeto que la conformó (i.e. coleccionistas, aficionados, arqueólogos, historiadores, entre otros). La acción social de seleccionar determinados objetos -que por su materialidad y condición testimonial del pasado son colocados al resguardo- está acompañada de microhistorias, las cuales dan cuenta de la presencia de discursos, posicionamientos éticos, políticos e ideológicos con respecto a la historia del poblamiento regional. Todo esto visibiliza el rol $\mathrm{y}$ agencia de la comunidad que han interactuado y continúan relacionándose con el patrimonio arqueológico prehispánico e histórico en pos de su conservación.

Otro de los ejes analíticos está dado por el rol que cumple la memoria de los individuos en la constitución de las colecciones arqueológicas en instituciones patrimoniales. En este sentido, se plantearon una serie de interrogantes que funcionaron como disparadores de la investigación, que a continuación se detallan: ¿En qué condiciones surgen las colecciones arqueológicas? ¿Qué significa para un objeto ser parte de una colección en un mu- seo? ¿Qué atributos hace que un objeto forme parte de una colección? ¿Son sus características materiales, estilísticas, su condición de testimonio del pasado, o tal vez las historias que acompañan al objeto durante su biografia las que las hacen parte de una colección? ¿Qué mecanismos de activación patrimonial desarrollan los diferentes actores de la comunidad con la cultura material arqueológica?

El presente trabajo tiene por objeto analizar la historia de vida de la colección arqueológica Cinquini-entendida como los objetos, saberes, microhistorias que acompañan la práctica patrimonial- del Museo Chasicó, partido de Tornquist (Figura 1), a partir de una perspectiva de estudio de la memoria de su curadora, la Licenciada Nora Cinquini. Asimismo, se propone reflexionar el rol que cumplen los actores que intervinieron en su conformación y registrar los modos de patrimonialización de los objetos arqueológicos que conforman la colección.

\section{El coleccionismo como práctica ¿Qué es una colección?}

La colección es entendida como una institución coextensiva al ser humano, en el tiempo y el espacio, la cual resulta del producto de un comportamiento sui generis consistente en formar colecciones (Pomian 1993). Concretamente el Consejo Internacional de Museos (ICOM) la define como al "Conjunto de objetos materiales e inmateriales... que un individuo o un establecimiento, estatal o privado, se han ocupado de reunir, clasificar, seleccionar y conservar en un contexto de seguridad para comunicarlo, a un público más o menos amplio" (Desvallées y Mairesse 2010: 26). Desde esta perspectiva, la entidad de la colección como tal se encuentra estrechamente relacionada al sujeto y/o institución que le dio origen. Cabe destacar que el vínculo que 


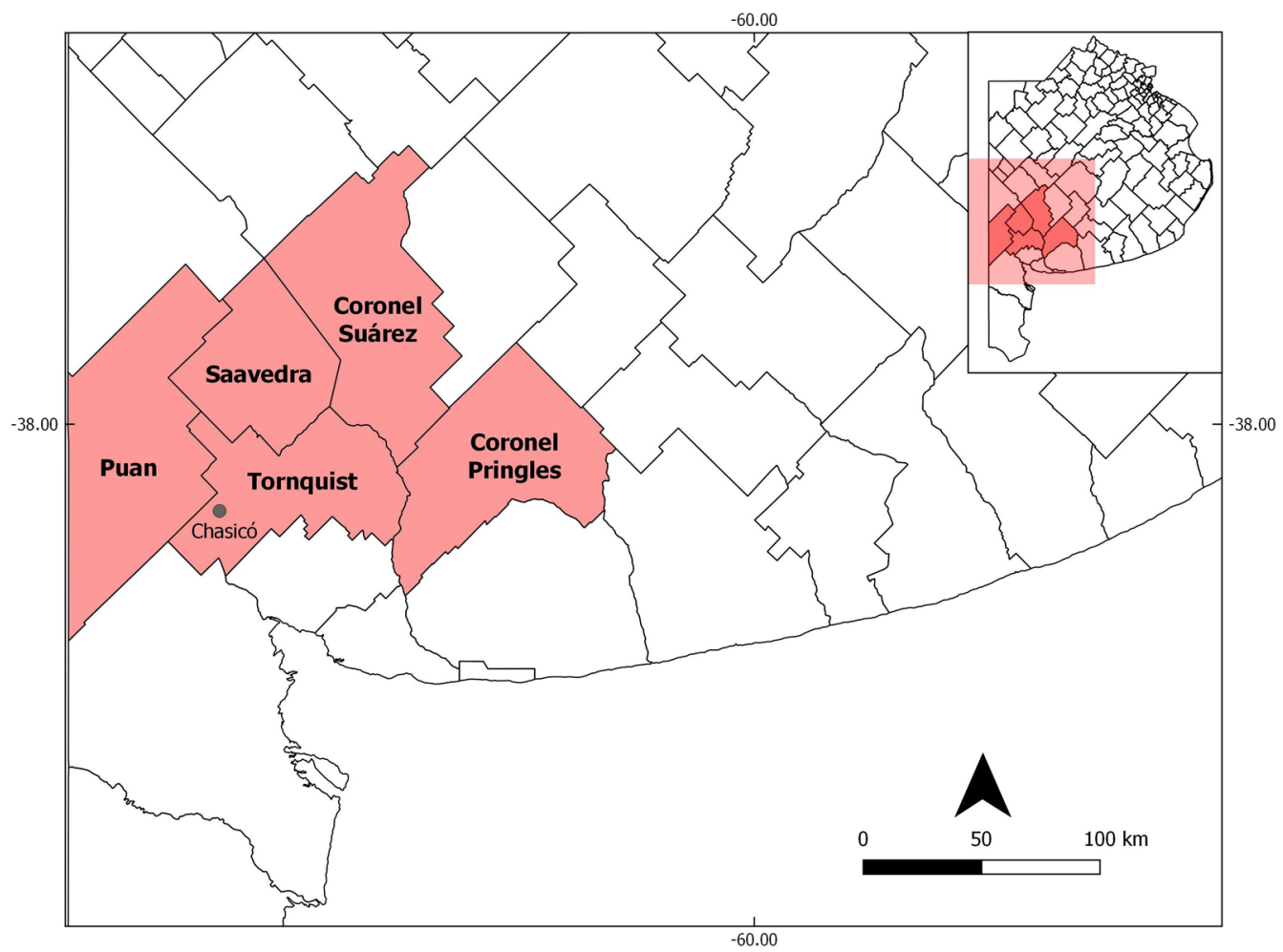

Figura 1. Ubicación de la localidad de Chasicó dentro de la Provincia de Buenos Aires. En rosa se señalan los partidos que comprenden el sector sur del Área Ecotonal Húmedo Seca Pampeana.

une al sujeto a los bienes que conforman la colección posee diferentes dimensiones, tales como la geográfica, social, económica e histórica. Esto da cuenta de las condiciones históricas contextuales de la colección y se vincula a la consideración de los objetos que conforman la misma, semióforos ${ }^{1}$ portadores de múltiples interpretaciones en su producción, su circulación y su consumo (Pomian 1993; 1999). Las condiciones de producción de la colección, se encuentra enlazada al contexto de su creación, a los sentidos otorgados por las comunidades a las cuales pertenecieron estos objetos. Por otra parte, en relación a la circulación y apropiación es interesante indagar las acciones llevadas a cabo por los sujetos en relación a los usos de los bienes materiales que conforman la colección (i.e. exhibición, estudio, intercambio de piezas, entre otras). Los objetos arqueológicos circulan y son consumidos en otros espacios sociales - más allá de los lugares reglamentarios e institucionales- que no han sido suficientemente problematizados por la arqueología.

Por otra parte, es importante considerar a las colecciones arqueológicas como espacios de exposición que vinculan diversos significados que emergen de la relación entre las personas y los objetos (Marques y Hilber 2012). Si bien al coleccionismo, como actividad recreativa, se la ha asociado en los imaginarios colectivos a una 
actividad narcisista y marginal por parte de sectores sociales acomodados (Pomian 1993), se trata de una práctica social de recuperación de soportes materiales de memoria que se remonta al siglo XV. En el año 1993 K. Pomian realizó un racconto sobre el papel cultural que tuvieron los coleccionistas durante la historia, en el cual el aparato estatal europeo aún no regulaba la circulación y salvaguarda de los bienes culturales. Este autor recupera, por una parte a intelectuales griegos como los principales responsables en publicar por escrito, en forma incipiente referencias respecto al estudio de las colecciones, y a los coleccionistas italianos, quienes desde el siglo XV fueron los primeros en colocar sus colecciones a disposición del público. Las primeras publicaciones oficiales que dan cuenta del estudio de colecciones aparecen en el siglo XVIII y estuvieron centradas en reconocidas obras de arte de algunas de las ciudades más importantes del mundo. Los historiadores estaban interesados en los circuitos de comercio del arte, las biografias de coleccionistas y la historia de las colecciones y museos con el sentido de realizar una reconstrucción de la ruta que determinada obra habia realizado a lo largo de su vida. También se estudiaban los gustos estéticos de los coleccionistas a partir de la interpretación de la selección de objetos que quisieron poseer individualmente. Este tipo de investigaciones, cuyo foco se reduce a la colección como fuente de belleza estética, dejó de lado a la colección como parte de la voluntad de interpretación del pasado por parte de los coleccionistas, sentimientos de curiosidad, religión o patriotismo (Pomian 1993). Por otra parte, la historia de la arqueología europea tanto la Tradición Escandinava -en el marco de un resurgimiento nacionalista- como la Escuela Franco Inglesa -en la búsqueda de la antigüedad del hombre europeo- dedicaron gran parte del siglo XIX a estudiar colecciones de bienes arqueológicos y a es- tablecer órdenes de estos conjuntos dentro de anticuarios y museos (Renfrew y Bahn 1991). En sintesis, el coleccionismo como práctica de vinculación social entre grupos del presente con el pasado posee una amplia trayectoria. Actualmente las colecciones de museos, tanto privadas como públicas, constituyen un tipo importante de evidencia analítica para el conocimiento de las sociedades del pasado (Panizza y Gavilán 2008).

\section{Coleccionistas ¿productores de saberes o saqueadores?}

El marco jurídico que interpela a las colecciones arqueológicas ha estado estrechamente vinculado a la regulación y legitimación de su estudio por parte de la comunidad científica. A comienzos del siglo XX, el 26 de febrero del año 1913 se decretó en la República Argentina la Ley de Ruinas y Yacimientos Arqueológicos, Ley Nacional $N^{\circ} 9080$, en la cual se contempló reglamentariamente por primera vez a los bienes arqueológicos. En el marco de la consolidación del Estado Nacional, esta ley promovió la investigación de aquellos vestigios materiales del pasado que eran de interés para la academia y la exclusividad de su estudio a este sector de la comunidad. En este sentido, la mirada científica desempeñó un papel crucial en relación a los objetos arqueológicos y los procesos de activación patrimonial. Entrado el siglo XXI, en el año 2003, la Ley 9080 fue derogada en el art. 58 de la nueva Ley Nacional 25.743/03. Esta "nueva" Ley Nacional se focalizó en la conservación patrimonial, de acuerdo a su artículo $4^{\circ}$ se sostiene que: "Serán facultades exclusivas del Estado nacional: a) Ejercer la tutela del Patrimonio Arqueológico y Paleontológico. En orden a ello deberá adoptar las medidas tendientes a su preservación, investigación y a fomentar la divulgación." (Ley Nacional 25.743/03, Artículo $4^{\circ}$ ). En esta línea, la mirada desde 
la comunidad científica hacia la práctica del coleccionismo ha estado fuertemente planteada en términos de ausencia de legitimidad y legalidad, concretamente se ha vinculado al coleccionismo como una práctica ilícita producto de acciones por fuera del marco de lo legal.

Cabe preguntarse por fuera de este marco legal: ¿Qué actores se encuentran "habilitados" a crear una colección arqueológica? ¿En qué medida el coleccionismo en un sentido conservacionista buscó llenar vacíos institucionales? Para Acosta Castro (2015) la recolección de materiales constituye una práctica que se encuentra en los márgenes del aparato estatal, tratándose de una práctica ilegal, pero que a la vez da cuenta del papel que tienen otros sujetos en relación a los bienes arqueológicos más allá del marco legal normativista nacional. Asimismo, este autor diferencia la intencionalidad del coleccionista, quien nunca ha planteado su práctica en términos de ilegalidad, de aquellos "saqueadores" quienes representan otro grupo social que también incide en el campo patrimonial, pero desde una óptica destructiva ya que ellos sí están plenamente conscientes de que cometen un delito al saquear sitios arqueológicos para su posterior comercialización. En este sentido, los coleccionistas tienen una agenda vinculada más con el estudio, documentación y conservación social del patrimonio que con una búsqueda de medios económicos y lucrativos a través del mismo. En otras palabras, la acción llevada a cabo por los coleccionistas se vincula al "rescate" y protección de las piezas que se pueden encontrar en los estratos superficiales de los sitios, los cuales se encuentran "desprotegidos", inminentemente expuestos a ser destruidos por el paso de automóviles, personas, tractores de carga, entre otros. Bajo esta lógica, llevan a cabo la práctica de guardar las piezas para su salvaguarda (Acosta Castro 2015). Por otra parte, se consideran otros dos tipos de categorias analiticas ideales que caracterizan la relación entre los sujetos y los objetos arqueológicos, éstas son la figura del aficionado -cuyo interés en los objetos arqueológicos responde al estudio de la historia, pero no a su divulgación- y la del diletante - aquellos sujetos que seleccionan objetos vinculados a su excentricidad y/o curiosidad-. Es importante aclarar que se trata de tipos ideales (saqueador, coleccionista, aficionado, y diletante), no encontrándose en "estado puro" en las prácticas de los sujetos y sus modos de producir sentido y relacionarse con la materialidad arqueológica.

\section{Colecciones y patrimonio arqueológico}

Desde una perspectiva que sostiene que el patrimonio es una construcción social, se consideran bienes patrimoniables a aquellos objetos reconocidos por la comunidad por su importancia histórica, vinculada a la memoria y los intereses y necesidades del presente. En otras palabras, se trata de objetos designados y reconocidos por una comunidad de tal manera que la memoria determina no sólo la relevancia de los referentes, sino también el contenido de los discursos que emergen de los objetos patrimoniables (Prats 2005). Además “...el patrimonio local está compuesto por todos aquellos objetos, lugares y manifestaciones locales que, en cada caso, guardan una relación metonimica con la externalidad cultural. Pero precisamente el factor escala introduce variaciones significativas en la conceptualización y gestión del patrimonio local" (Prats 2005:23-24). En este sentido cabe preguntarse: ¿Qué rol cumplen las diferentes comunidades en relación a la patrimonialización de las colecciones? ¿Qué actores pueden conformar colecciones patrimoniables? La comunidad desempeña un rol fundamental en el otorgamiento de sentidos a determinados objetos en el proceso de conformación de una co- 
lección, ya que son elegidos por determinados actores como anclajes de memoria, estrechamente vinculados a necesidades del presente, más allá de su regulación normativa (Acosta Castro 2015). Los procesos de patrimonialización de los objetos dan cuenta del vínculo de las comunidades con su pasado y en este sentido este trabajo busca indagar las formas de agencia que poseen determinados actores sociales en los procesos de patrimonialización de la colección Cinquini. Específicamente, se analizarán las micro-historias que acompañan las biografias de la colección, de los coleccionistas y de la familia Cinquini a través de la memoria oral de uno de sus integrantes: Nora Cinquini.

\section{Metodologia}

\section{El estudio del relato oral}

Se considera que el estudio de la memoria de los coleccionistas aporta un eje fundamental de análisis en relación a las dimensiones sociales, históricas, políticas e ideológicas que atraviesan la selección de objetos que forman las colecciones. Dicho de otra manera, constituye una herramienta analitica que permite rastrear de qué manera interviene como evocadora de aprendizajes de la historia personal y colectiva, así como los sentidos atribuidos por un grupo a determinadas experiencias y objetos (Cardini 2005). La memoria se apoya en recuerdos borrosos, en espacios concretos, en imágenes y "cosas". Los bienes culturales que integran las colecciones se vuelven en estos contextos, soportes de memoria y centro de discusiones politicas ideológicas, por la imposición de perspectivas acerca de la sociedad, la historia y su memoria colectiva que los mismos conllevan. Trabajar con la memoria oral supone indagar en la memoria colectiva las formas de la identidad local, sus relatos y vaive- nes; el imaginario social, sus representaciones y formas de construcción e institucionalización de lo social (Gili 2016). El relato oral ofrece la posibilidad de observar la estrecha relación que existe entre experiencia y narración de los hechos, ya que el relato es el registro de la experiencia que conjuga la elaboración con la transmisión de lo vivido. En el relato aparecen las visiones compartidas por un grupo de pertenencia, aquellas tradiciones y lecturas de la realidad que se acumulan y sedimentan en torno a narrativas, nuevas y viejas formas propias de verse. En este sentido, resulta útil la categoría analítica de "coleccionista organizativo", la cual hace hincapié en el sentido organizativo que dota a la colección de un orden vinculado con la ruta de vida de la persona que adquiere una pieza y el objeto que se integra a la colección (Acosta Castro 2015). Es la estructura simbólica que le da sentido a la narrativa de una colección como conjunto. El coleccionista organiza, selecciona, ordena, de modo tal que cada pieza que compone una colección, se transforma, se descontextualiza de su lugar de origen y se resignifica en un nuevo orden. Pero también armoniza su espacio cotidiano con las piezas, tiende puentes lejanos en el tiempo ingresando los recuerdos a su hogar. De esta manera existe un vínculo emotivo que une al coleccionista a las piezas, cada objeto posee una historia y un sentimiento detrás, además él organiza sus recuerdos a través de los elementos; el momento de encontrar o adquirir alguna pieza, se convierte en parte de su historia de vida, se detona así un valor simbólico que integra al objeto y al coleccionista (Acosta Castro 2015).

Por todo lo expuesto, es interesante retomar los aportes de los estudios biográficos para el estudio de los procesos de constitución de colecciones arqueológicas (Kopytoff 1986). Es de amplio conocimiento que desde sus inicios, la antropología ha 
trabajado con los relatos de vida (Buechler 1999) como una herramienta que permite conocer el universo de símbolos y formas de representación que elaboran las personas en sus interacciones sociales, económicas y políticas a lo largo de sus trayectorias vitales. Los modos de interacción de los individuos de una comunidad con determinados objetos, lugares y manifestaciones se relacionan intensamente con sus biografias. Es así como:

“... la memoria determina los referentes en que la comunidad va a fijar sus discursos identitarios, con un carácter casi totémico, pero también los contenidos mismos de esos discursos. La memoria compartida, antes que colectiva, es, por supuesto, una construcción social, como es una construcción también, de carácter más o menos individual, la memoria biográfica. La memoria es cambiante, selectiva, diversa, incluso contradictoria y relativa en todo caso a las situaciones, intereses e interrelaciones del presente..." (Prats 2005:26).

Se considera que, mediante el estudio de la historia oral de los coleccionistas, es posible aproximarse a una cantidad de relatos respecto de hechos no registrados por otro tipo de documentación, o cuya documentación se desea completar (Pereira de Queiroz 1991). En consecuencia, en esta investigación se concretaron una serie de entrevistas realizadas a la coleccionista Nora Cinquini durante los años 2010-2017, en ellas se buscó registrar su experiencia en relación a la conformación de la colección que el Museo Arqueológico de Chasicó custodia. En este sentido, cabe destacar que "lo importante es que sean captadas las experiencias del entrevistado. Él es quién determina qué es relevante o no para ser narrado, él es quien tiene el hilo conductor. Nada de lo que relata puede ser considerado superfluo, pues todo se encadena para componer y explicar su existencia" (Pereira de Queiroz 1991:7-8). El relato de un narrador sobre su existencia a través del tiempo, intenta reconstituir los hechos que vivió y transmitir la experiencia que adquirió mediante la formulación de una narrativa lineal de los acontecimientos que se consideran significativos, hay una selectividad de lo que se desea recordar (Del Valle Aquino 1998). De modo tal que se permite entrever las relaciones con los miembros de su grupo, de su profesión, de su clase social, de su sociedad global. De esa forma, los relatos transmitidos por la historia oral siempre transcienden el carácter individual del sujeto entrevistado y se inserta en la historia de las colectividades a las cuales el narrador pertenece (Pereira de Queiroz 1991, Veras 2010). En virtud de ello, analizar la historia oral de Nora en relación a la conformación de la colección arqueológica, es también identificar las relaciones que sus contemporáneos establecieron con el pasado y el patrimonio arqueológico.

\section{El origen del museo arqueológico de Chasicó}

El Museo Arqueológico de Chasicó se encuentra emplazado en una estancia privada a pocos kilómetros de la localidad de Chasicó, partido bonaerense de Tornquist. Según el último censo realizado este municipio cuenta con 12.676 habitantes (INDEC 2010), y forma parte del sector sur del Área Ecotonal Húmedo Seca Pampeana (Oliva 2006; Oliva et al. 2010; Oliva et al. 2015). Esta región poblada desde el Holoceno Medio (Castro 1983) ha sido extensamente estudiada (Oliva 1991; Oliva et al. 2010, 2015) debido a la presencia de considerables y múltiples formas de registro material arqueológico (i.e. cuevas y aleros con arte rupestre, piedras paradas y estructuras de piedras, sitios en superficie y estratigrafia, entre otros). Asimismo, esta área constituyó un espacio de contacto interétnico dentro de los límites en expansión del área de frontera del Estado Nacional a fines del si- 
glo XIX (Devoto et al. 2016; Panizza 2015).

Luego de la llamada "Conquista al Desierto" de 1879, se produce la efectiva ocupación del área por parte del Estado Nacional, con el asentamiento de los primeros establecimientos agrícola-ganaderos. En este marco de constitución de las primeras estancias de la zona, se conforma el establecimiento "Don Natalio", en cuyo predio se construye una casa chorizo en 1910 con las técnicas tradicionales de alambre, barro y paja trenzada, cuyas condiciones de conservación son actualmente óptimas; por este motivo fue declarada sitio de interés Histórico Cultural por la Provincia de Buenos Aires en 2006. La casa utilizada como sede del museo fue construida por Natalio Cinquini como un símbolo de perdurabilidad en el tiempo. Nora, su nieta, afirma que "Yo siempre digo que el origen del museo está en un manojo de llaves que guardó mi abuelo..." (Nora Cinquini comunicación personal octubre de 2017), es en esta edificación donde ha funcionado el museo durante cuatro décadas (Figura 2).

No es posible analizar las colecciones de un museo sin mencionar la agencia del o de los sujetos que las conformaron. En este sentido, es de interés abordar la memoria oral de la Lic. Nora Cinquini, tutora y co-creadora de lo que actualmente constituye una de las colecciones más grandes del sudoeste bonaerense.

El museo posee tres salas, que documentan la historia del paisaje y la biota regional (en los cuales se exhiben restos paleontológicos y especímenes disecados), la vida de los primeros habitantes en la zona y el proceso de colonización de Chasicó (Figura 3). En este sentido, la institución cuenta con materiales arqueológicos regionales y alóctonos, producto de la recolección regional y en viajes realizados a otras áreas geográficas. A modo de ejemplo puede mencionarse la colección arqueológica Ybarra, en la cual Nora tuvo una participación activa en su conformación. Se trata de una colección cuyo número de piezas llega a 5.000, provenientes del sitio arqueológico que lleva el mismo nombre, ubicado en el margen derecho de río Sauce Chico en la provincia de Buenos Aires. Está integrada por fragmentos de cerámica, cuentas de collares, restos óseos, placas grabadas, manos de molinos, morteros, instrumentos de piedra, y desechos de talla, entre otras piezas (Panizza y Gavilán 2008).

La colección arqueológica que posee el museo es producto de la recolección, selección de determinados objetos, su or-
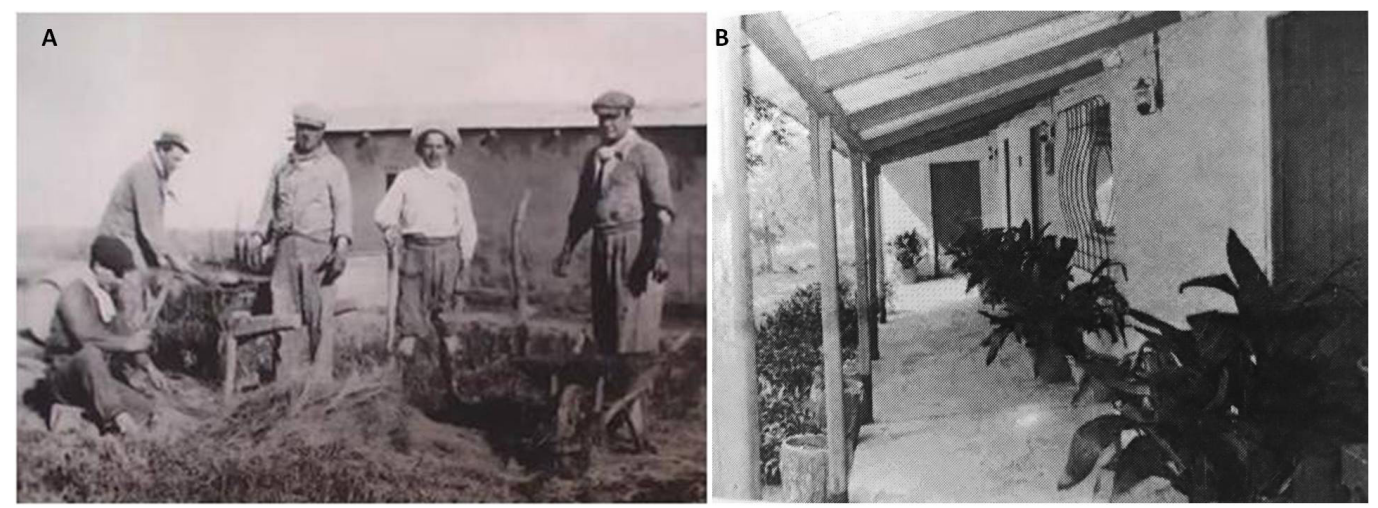

Figura 2. a) Construcción de la casa de adobe 1910, que será desde el año 1971 la sede del Museo Arqueológico de Chasicó, partido de Tornquist. b) Vista actual del lateral del rancho. Fuente: Nora Cinquini. 


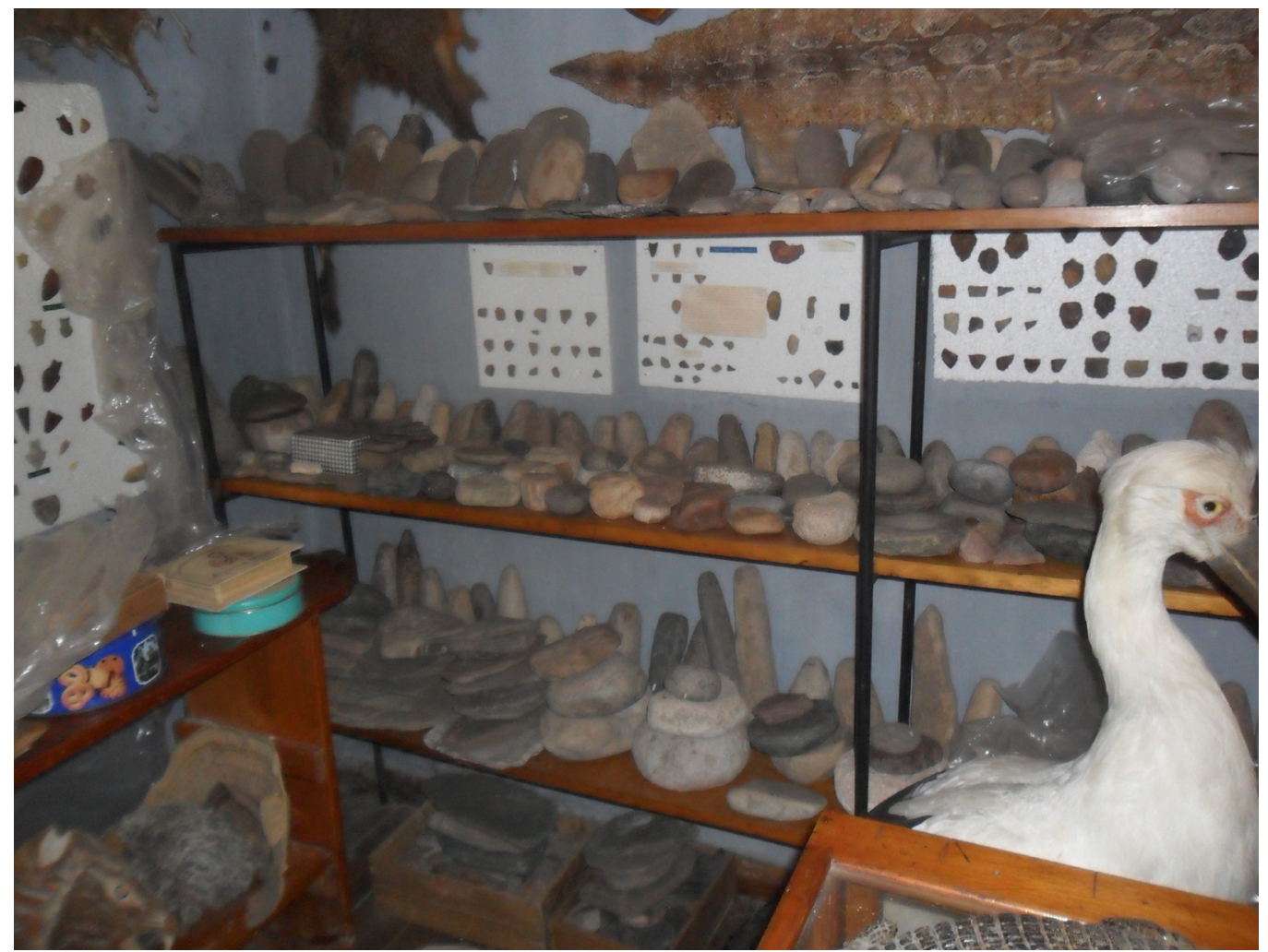

Figura 3. Piezas de la colección Cinquini. Fuente: M. Cecilia Panizza.

denación y posterior interpretación (Prats 2005) por parte de tres generaciones. La primera generación representada por $\mathrm{Na}$ talio Cinquini, migrante italiano, quien llegó a Argentina a fines del siglo XIX. En el año 1888 Natalio trabajó como carrero en la Ciudad de Buenos Aires, luego de pocos años se trasladó a El Perdido -actual estación José Guisasola partido de Coronel Dorrego- para trabajar en actividades agrícola ganaderas en contextos rurales. Desde allí migró a la localidad de Saldungaray, partido de Tornquist. Por las características geográficas que presentaba el lugar, similares a la región toscana de la cual procedia, decidió formar parte de un proceso de colonización regional por parte de migrantes italianos y dinamarqueses que ocuparon el partido de Tornquist de forma permanente, en primera instancia en Saldungaray y luego en la localidad vecina de Chasicó. En este sentido Nora cuenta, "Mi abuelo conformó un proceso de colonización con colonos dinamarqueses e italianos, que los trajo aqui don Guillermo González. Don Guillermo González era un político de influencia en la provincia" (Nora Cinquini, octubre de 2017). De esta manera, a partir del año 1910 se establece la familia Cinquini en dicha localidad. Una segunda generación familiar estuvo representada por Tomás Cinquini, hijo de Natalio y padre de Nora Cinquini. Luego de Nora continúan dos generaciones posteriores, su hijo y 
nietos, poblando el territorio, sin embargo ellos no han dado continuidad a las actividades del Museo Arqueológico de Chasicó ni tampoco perpetuaron las actividades de activación patrimonial que emergian del museo. Las biografias de las primeras tres generaciones de la familia Cinquini están estrechamente vinculadas con la conformación de la colección arqueológica del Museo, su cotidianeidad con la materialidad arqueológica en inmediaciones del establecimiento donde vivian los convirtieron en agentes directos para con la formación de la institución museística. En este sentido, Nora recuerda que,

“...después que me casé que volví al campo era un poco mi deleite salir con un jeep y un perrito que tenia Choki, este saliamos. Siempre en la cuenca de los arroyos, del arroyo Chasicó y el Rio Sauce Chico. Era época de sequía, entonces los médanos, con los vientos dejaban material, vos te dabas cuenta dónde estaban los sitios. Y habia una cantidad de material... y fue cuando yo lo fui a ver al doctor Austral, porque ¿qué hacemos con tener diez cajas de zapatos llenas de material sino cumple una función cultural? Ya sea desde el punto de vista didáctico, o educativo... (Fragmento de entrevista a Nora Cinquini octubre de 2017).

Cabe destacar que el Museo Arqueológico de Chasicó se caracterizó por ser pionero en cuanto a las actividades que hoy denominariamos como de educación patrimonial. El propio origen del Museo se encuentra ligado a los establecimientos educativos formales de la localidad de Chasicó, ya que se fundó el 12 de Octubre de 1971 con el propósito de reunir fondos para las escuelas regionales, en ese momento sólo existía el nivel básico y las cooperadoras Escolares. Se considera que este museo podría ser considerado como un patrimonio localizado en sí mismo, en términos de Prats, ya que trasciende su ubicación y es capaz de provocar por sí mismo flujos de visitantes con relativa independencia (Prats 2012). En una serie de entrevistas realizadas a Nora expresó en diferentes pasajes que fue iniciativa de su padre armar un museo en la Estancia Natalio, donde ellos vivian. En este sentido, relató que:

"Quedó mi padre a cargo de todo esto. Fue idea de él, Tomás Cinquini se llamaba mi padre, de hacer ese museo... esa casa que el abuelo pidió, que hizo con sus manos, que nunca la deshicieran, y que sea guardada, sea digamos perdure en el tiempo, un día almorzando mi padre dice ¿por qué no hacemos un museo? Por los chicos de las escuelas van acá? Tienen que ir a Bahía Blanca o a Santa Rosa para ver un museo. Tornquist ni tenía todavia museos. Entonces bueno, lo hacemos en el rancho. Así nació el museo en el rancho..." (Fragmento entrevista, Nora Cinquini, diciembre de 2010).

“...Quizás un poco mi padre, que era autodidacta también pero leía muchísimo, y dice ¿qué podemos hacer con todo este material que tenemos?... Y yo digo donarlo a un museo, vamos a intentarlo. En Tornquist ni hablar, porque nadie sabia. Era en esa época, un museo era el cuco y vine a Bahía y hablé con la gente del museo de acá porque la conocía y me dicen Nora ¿sabes que pasa para los museos? Nunca hay plata... Bueno, le conté a mi padre, y me dice bueno mira vamos a agarrar el rancho del abuelo, lo vamos a hacer museo, y así empezó..." (Fragmento de entrevista a Nora Cinquini, octubre de 2017).

"Y lo primero que hice cuando volvi al campo fue dedicarme a los museos. Al museo que habia en casa que era chiquito, organizarlo. Más ir a visitar las escuelas y había pedidos, muchos, del ámbito rural que en aquellos años iA dónde iban? Tenian que viajar a Bahía Blanca o a Santa Rosa... Eran distancias enormes. Entonces era como que el museo iba a la escuela (...) Y bueno habia mucho interés (...) el gran público fueron las escuelas... (Fragmento de entrevista a Nora Cinquini octubre de 2017).

Se considera que el museo posee un fuerte sentido de pertenencia y arraigo al territorio, no sólo en relación a las piezas que exhibe sino que también, según los fragmentos de las entrevistas, la motivación de la creación del Museo Arqueológi- 
co de Chasicó viene dada por la demanda social concreta de no poseer este tipo de instituciones dentro del partido de Tornquist. Una petición que asimismo vincula a la institución museística con los establecimientos educativos formales. La capacidad de agencia del Museo Arqueológico de Chasicó no estuvo aislada de su contexto social, ya que siempre estuvo marcada por un fuerte sentido colectivo. En la memoria institucional, en sus años de apogeo el Museo recibía visitas de estudiantes de diversos establecimientos educativos de distintas partes del país y del extranjero. En la entrevista realizada en octubre de 2017, Nora relató detalladamente la experiencia de haber recibido a un curso de estudiantes de un colegio francés como uno de los acontecimientos más importantes que le tocó vivir dentro. El motivo de esta visita era acercarse no sólo a la historia de la región del sudoeste bonaerense sino a lo que significaba "ser argentino", en palabras de Nora las costumbres y tradiciones propias de lo nacional. Este hecho refuerza aún más la idea del museo como un espacio de memoria colectiva para la comunidad de Chasicó.

\section{Tejiendo redes: la colección Cinquini}

El Museo Arqueológico de Chasicó, institución de tipo tradicional, se caracteriza por haber ido creciendo a medida que lo hacía la colección que custodia (Pomian 1990). A lo largo del tiempo se han identificado al menos cuatro estrategias de obtención de piezas arqueológicas. Una primera estrategia está dada por la recolección superficial autodidacta que fue llevada a cabo tanto por Nora Cinquini como por su padre en la Estancia Don Natalio. Estrechamente vinculada a esta primera estrategia, se encuentra la recolección de materiales del suelo que habrían sido hallados posteriormente a la remoción del terreno por máquinas asociadas a las ac- tividades agrícolas desarrolladas en el predio (arado, cosechadora, entre otras).Una tercera estrategia se vincula a la relación de Nora con las Universidades Nacionales del Sur (con sede en Bahía Blanca), La Plata y Rosario. Desde los primeros hallazgos de material arqueológico Nora buscó vincularse con arqueólogos para el estudio de los sitios que ella había identificado, con el fin de producir conocimiento respecto a los pueblos indígenas que vivieron en el pasado en el sudoeste bonaerense. En este sentido, colaboró activamente en excavaciones arqueológicas llevadas a cabo por diferentes equipos que trabajaron la región, primero a cargo de Antonio Austral y luego de Fernando Oliva.

Finalmente, la cuarta estrategia por la cual la colección fue incrementándose a partir de donaciones se relaciona al lugar destacado que ocupa Nora en la región, no sólo dentro del partido de Tornquist, sino dentro de la Provincia de Buenos Aires como especialista y conocedora de la historia. Cabe destacar que ella fue premiada y reconocida por diferentes instituciones en numerosas oportunidades por su labor en pos de la difusión de la historia bonaerense. Por ejemplo, obtuvo un reconocimiento del Honorable Concejo Deliberante de Tornquist por la "Labor Ciudadana" en el año 2006; el reconocimiento como "Mujer Innovadora" por la Honorable Cámara de Senadores de la Provincia de Buenos Aires en el año 2007; recibió el Premio "Mujer Destacada" por el Gobierno de la Provincia de Buenos Aires 2012 y un reconocimiento por "Trayectoria en la Comunidad" de la Municipalidad de Tornquist en el año 2015, entre otros. En este sentido, por el reconocimiento otorgado por la comunidad hacia su persona fue convocada en numerosas oportunidades por vecinos de Chasicó y de localidades aledañas cuando "aparecía" material arqueológico o paleontológico. Se puede citar el caso del hallazgo de un ejemplar de Glyptodon en un campo 
privado removido por un arado, en la década de 1970. En esta época el Estado no reglamentaba la extracción ni cuidado del patrimonio arqueológico y paleontológico, por lo cual los dueños del campo acudieron a Nora para que lo extrajera, tarea que fue llevada a cabo con gran esfuerzo y compromiso en pos de preservar el resto paleontológico. Por todo lo expresado, se puede afirmar que la historia de la colección da cuenta del arraigo de la coleccionista, y de la construcción identitaria vinculada a los procesos históricos desarrollados regionalmente.

Dentro de la historia del Museo Arqueológico de Chasicó hubo períodos de más actividad que otros, esta fluctuación se relaciona con la agencia de Nora en las distintas etapas que atraviesa de su vida. En sus años como docente, en numerosos establecimientos educativos, asumía una fuerte agenda vinculada a la educación patrimonial, fue un período durante los cuales el museo estrechó fuertes lazos con la comunidad educativa del partido de Tornquist y otros municipios aledaños. Asimismo, Nora relata en las entrevistas sus años de juventud en los cuales salía a recolectar material para el museo. Actualmente las acciones de activación patrimonial llevadas a cabo en el museo se encuentran en decaimiento, ya que el establecimiento permanece cerrado al público debido a que Nora ya no vive en la Estancia Don Natalio. Se considera que existe una estrecha vinculación entre la biografia del coleccionista y la institución, de modo tal que los procesos de activación patrimonial que surgían de la interacción de ambas partes están muy ligadas a la figura y capacidad de agencia de Nora. Sin embargo esta institución no previó formar recursos humanos que pudieran sostener el funcionamiento del museo, así como la conservación, preservación, exhibición y difusión de este valioso patrimonio. A raíz de ello, actualmente las funciones que caracteriza- ron a la institución -conservar, registrar, investigar, interpretar, difundir socializar, exponer- durante la curaduría y gestión de Nora, se encuentran interrumpidas, sin que se perciba una clara agenda en relación al futuro de la institución.

\section{Discusión}

\section{La patrimonialización de los objetos arqueológicos de la colección Cinquini}

Durante el acto de crear una colección, se pone en juego no solo la recolección de determinados objetos a partir de la puesta en valor de los mismos, sino también aquellos procesos que se denominan de activación patrimonial. El proceso de patrimonialización de una colección de objetos arqueológicos implica por una parte la sacralización de la externalidad cultural, es decir el deseo de preservar aquellos materiales que dan cuenta de la vida de un "otro cultural" que ya no se encuentra presente en la actualidad (Prats 2005). En este caso, en relación a la colección arqueológica se trata de la sacralización de los objetos de los pueblos indígenas que fueron despojados de sus tierras tras el período temporal que abordó las campañas de la Conquista del Desierto (1878-1885). Por otra parte, en el caso de estudio se llevó a cabo también la sacralización de las colecciones arqueológicas históricas que Nora denomina de "Nuestros ancestros los abuelos" correspondientes a los materiales que dan cuenta de la fundación y poblamiento histórico de Chasicó. El proceso de patrimonialización implica además de la denominada sacralización de la externalidad cultural, un proceso de activación patrimonial que en el caso del Museo Arqueológico de Chasicó, se llevo a cabo por más de cuatro décadas bajo la agencia de Nora Cinquini. Se han desarrollado en la institución una serie de procesos en tor- 
no a los objetos que se desea exhibir y destacar, a través de su puesta en valor y su descripción, donde por una parte se acentuaron los atributos de los objetos arqueológicos así como también los sentidos otorgados a los mismos. Estas acciones forman parte de los denominados mecanismos de activación patrimonial (Prats 2005). De la misma forma, integran parte de estos procesos los discursos producidos a partir de la exhibición de los objetos de la colección, así como también las diversas actividades de educación patrimonial que el museo gestionó (talleres y charlas de arqueología en establecimientos educativos de nivel básico y superior, charlas en organizaciones civiles, muestras rotativas de material arqueológico, entre otras). La activación patrimonial de la colección Cinquini se vio fuertemente influenciada por la agencia de Nora en pos de comunicar sus investigaciones y trazar puentes entre el pasado regional y el presente a través de prácticas de difusión concretas.

Es interesante destacar como los sentidos producidos por los actores que conforman las colecciones se encuentran relacionados a las biografias de los mismos; siendo de esta manera la colección un registro de las diferentes generaciones que participaron en su conformación. Tal es el caso de la familia Cinquini, en la cual Natalio Cinquini fue parte de las familias fundadoras que se asentaron en el territorio correspondiente a la localidad de Chasicó. En este sentido, el modo en cómo se construyen lazos sobre la historia desde el presente se traduce en prácticas de patrimonialización de determinados objetos de la cultura material de los pueblos que vivieron en el pasado.

En sintesis, la activación patrimonial se correlaciona con discursos generados por la institución, en este caso por Nora Cinquini, los cuales implicaron la selección de determinados objetos, su ordenación y posterior interpretación (Prats 2005). Las narrativas elaboradas por Nora son, en este sentido, formas de representación del patrimonio arqueológico vinculadas con su vida personal, fuertemente impregnadas por el carácter emotivo que se encuentra impreso en la colección. De esta manera, a través de la colección ella construye una narrativa donde su propia existencia cobra sentido, así como también configura una mirada y una forma de apropiación social del patrimonio en la cual nombra "Cinquini" a la colección. La constituye bajo el nombre de su propio apellido y esto es su modo de dejar una huella sobre los objetos, que legitiman simbólica y materialmente la ocupación histórica y poblamiento de un territorio determinado-. En este sentido, el Museo Arqueológico de Chasicó puede pensarse como un espacio idóneo de activación de memoria colectiva, en el cual emergen pasados múltiples.

\section{Consideraciones finales}

Los procesos de emergencia de colecciones arqueológicas, y la consecuente creación en algunos casos de repositorios e instituciones museísticas a partir de éstas, deben ser abordados no solo desde una mirada legalista. Por lo expuesto, se considera que el coleccionismo como práctica no debe ser pensado sólo como uno de los factores que inciden en la conservación de los sitios arqueológicos, sino como un fenómeno que permite visibilizar de qué manera otros agentes interactúan activamente con la cultura material e intervienen en la construcción de lo patrimoniable. Es posible y recomendable elaborar estudios sobre cómo actúa el patrimonio en las dimensiones sentimentales, emotivas y subjetivas de la población (Acosta Castro 2015).

Finalmente cabe destacar que los procesos de activación del patrimonio dependen fundamentalmente de los poderes po- 
líticos (Prats 2005), esta afirmación tiene su correlato positivo en el Museo Arqueológico de Chasicó, ya que sin la agencia de Nora Cinquini, las medidas de activación de patrimonialización permanecen postergadas. Considerarla en clave de agente de activación patrimonial, implica pensar su subjetividad fuertemente arraigada a la de la colección arqueológica. Adhiriendo a Ortner (2016) los procesos constitutivos de los sujetos se relacionan con los estados internos de los individuos, es decir con sus deseos, pensamientos y afectos entre otros, en relación a los elementos culturales que le son impuestos por el entorno. En este sentido, para entender el surgimiento e historia de vida de la colección arqueológica del Museo Arqueológico de Chasicó, es necesario y pertinente entender la biografia y desde qué lugar Nora Cinquini como coleccionista, como mujer, nieta de la primera generación de pobladores de un área seleccionó, estudió, ordenó y cuidó los objetos que formaron parte de su vida y de la historia de vida de la colección.

En relación a la dimensión política de la patrimonialización de la cultura material, cabe destacar que Nora señala la ausencia de apoyo municipal en las acciones de divulgación que la institución realizó. En sus palabras en relación a si el museo recibió alguna vez algún tipo de ayuda del municipio afirmó que: "Nunca jamás jamás, igual que todas las visitas a las escuelas, a instituciones... pero no, gracias a la familia que era una cosa que haciamos juntos porque te apoyaban económicamente. Primero mientras estaba soltera mi padre, después el campo, mi marido siguió..." (Comunicación personal Nora Cinquini, octubre de 2017). En virtud de ello, puede sugerirse que no hubo una vinculación histórica entre la dueña del Museo y las políticas públicas de nivel municipal en pos de la conservación patrimonial, si bien ella tuvo reconocimiento social, no se tradujo en estrategias de perdurabilidad de la institución, que al presente se encuentra cerrada al público. En este sentido, el Museo Arqueológico de Chasicó, no ha encontrado un acompañamiento adecuado a nivel operativo, al depender exclusivamente de la voluntad y esfuerzo de Nora.

\section{Agradecimientos}

A M.C. Panizza por la lectura y acompañamiento del manuscrito, a N. Morales por el mapa; a F.W.P. Oliva por presentarme a Nora Cinquini, a quién le estoy profundamente agradecida por la calidez de sus palabras y la generosidad en la transmisión de su valioso conocimiento. A la Universidad Nacional de La Plata, institución que financió este trabajo a través del otorgamiento de una beca de investigación doctoral.

\section{Notas}

1 Se utiliza la noción de semióforo para referirse a aquellos objetos portadores de significados cambiantes según sus diferentes funciones (ver Pomian 1999).

\section{Bibliografia}

ACOSTA CASTRO, A. 2015. El coleccionismo como apropiación social del patrimonio arqueológico. Notas para pensar en los márgenes del Estado desde San Agustín, Jalisco. Actas del IV Congreso Latinoamericano De Antropología "Las antropologias latinoamericanas frente a un mundo en transición", pp. 1-20. UNAM, Ciudad de México.

BIASATTI, S. 2012. Coleccionar objetos arqueológicos: "Esto no está aquí por nosotros, nosotros estamos aquí por esto". En Entre Pasados y Presentes III. Estudios Contemporáneos en Ciencias Antropológicas. Editado por N. Kuperzmit, T. Lagos Mármol, L. Mucciolo y M. Sacchi, pp. 383-397. MNEMOSYNE, 
Buenos Aires.

BUC, N. y V. CORONEL. 2013. Revisando la colección de instrumentos óseos de L.M. Torres (D25 Museo De Ciencias Naturales De La Plata). Revista Arqueología 19(2):245-264.

BUECHLER, H. 1999. El rol de las historias de vida en antropología. Areas: Revista Internacional de Ciencias Sociales 19:245-264.

CARDINI, L. 2005. La memoria como herramienta; reflexiones sobre las prácticas artesanales en Rosario. Revista de la Escuela de Antropología (UNR) X:93107.

CASTRO, A. 1983. Noticia preliminar sobre un yacimiento en la Sierra de la Ventana, Sierras Australes de la Pcia. de Buenos Aires. Relaciones XV(N.S.):91-107.

DEL VALLE AQUINO, R. 1998. La memoria colectiva en la construcción de la identidad. Actas del $1^{\circ}$ Congreso Internacional sobre Patrimonio Histórico e Identidad Cultural, pp. 127-134. Editorial Magna. Tucumán.

DESVALlÉES, A. y F. MAIRESSE. 2010. Conceptos claves de museología. ICOM. International Committee for Museology (ICOFOM). https://icom.museum/es/ ressource/conceptos-claves-de-museologia/

DEVOTO, M.G.; M.C. PANIZZA y F. OLIVA. 2016. La frontera militar en el Sistema Serrano de Ventania a fines del siglo XIX. Revista TEFROS 14(2):63-86.

FARRO, M. 2009. La formación del Museo de La Plata. Coleccionistas, comerciantes, estudiosos y naturalistas viajeros a fines del siglo XIX. Prohistoria Ediciones, Rosario.

KOPYTOFF, I. 1986. La biografia cultural de las cosas: La mercantilización como proceso En: La vida social de las cosas. Perspectiva cultural de las mercancias, editado por A. Appadurai, pp 89-122. Grijalbo, México.
MARQUES, M. y K. HILBER. 2012. Coleçoes e coleccionadores: vozes da exposiçao. Vestigios. Revista Latinoamericana de Arqueología Histórica 6(2):67-85.

OLIVA, F. 1991. Investigaciones Arqueológicas Desarrolladas en el Sector Occidental del Sistema de Ventania y la Llanura Adyacente. 1987-1989. Boletín del Centro de Registro Arqueológico y Paleontológico de la Provincia de Buenos Aires 1:39-41

OLIVA, F. 2006. Usos y contextos de producción de elementos "simbólicos" del sur y oeste de la provincia de Buenos Aires (República Argentina). Revista de la Escuela de Antropologia (UNR) XII: 101-116.

OLIVA, F.; M. ALGRAIN; M.C. PANIZZA; L. CATELLA y J. MOIRANO. 2010 Estudios arqueológicos en el Área Ecotonal Húmeda Seca Pampeana. Anuario de Arqueologia (UNR) 2: 201-214.

OLIVA, F. y M.C. PANIZZA. 2015. Investigaciones Arqueológicas en el Área Ecotonal Húmeda Seca Pampeana. En Ciencia y tecnología 2015: divulgación de la producción científica y tecnológica de la UNR, editado por C. López, pp. 10771083. UNR Editora, Universidad Nacional de Rosario, Rosario.

OLIVA, F.; M.C. PANIZZA; L. CATELLA; J. MOIRANO; N. MORALES; M. ALGRAIN; G. DEVOTO; L. IANNELLI; C. OLIVA; B. PEREYRA y A. SFEIR 2015. La construcción del pasado arqueológico en diferentes sectores del Área Ecotonal Húmedo- Seca Pampeana. Investigación y Extensión desde el Centro de Estudios Arqueológicos Regionales. Revista de Antropología del Museo de Entre Ríos 1(2):91102.

OTTALAGANO, F. Acerca de pequeños museos en pequeñas comunidades: el caso de Villa Cañas. Apuntes del CEAR 2:3137.

ORTNER, S. 2016. Antropologia y Teoria Social. Cultura, poder y agencia. UN- 
Oliva C. - "Historia de vida de una colección. El caso del Museo Arqueológico de Chasicó ..."

SAM, San Martín.

PANIZZA, M.C. y M. GAVILÁN. 2008. Arqueología en el Museo. Un acercamiento al estudio de las colecciones. El caso del Museo Regional de Chasicó, Partido de Tornquist. Apuntes del CEAR 2:113122.

PANIZZA, M.C. 2015. El área de Ventania en la conformación de la línea de frontera durante el siglo XIX. Cambio y diversidad cultural en la apropiación del paisaje. Revista TEFROS 13(2):83-107.

PEREIRA DE QUEIROZ, M. I. 1991. Relatos orais: do 'indizivel' ao 'dizivel'. En Variações sobre a técnica do gravador no registro da informação viva, edotado por M.I. Pereira de Queiroz, pp. 1-26. T.A. Queiroz, São Paulo.

POMIAN, K. 1993. La colección, entre lo visible y lo invisible. Revista de Occidente 141:41-50

POMIAN, K., K. 1999. Historia Cultural, historia de semióforos. En Para una historia cultural, editado por J. Rioux y J.F. Sirinelli, pp. 73-100. Taurus, México.

PRATS, L. 2005. Concepto y gestión del patrimonio local. Cuadernos de Antropología Social 21: 17-35.

PUPIO, M.A. 2005. Coleccionistas de objetos históricos, arqueológicos y de ciencias naturales en museos municipales de laprovincia de Buenos Aires en la década de 1950. História, Ciências, Saúde - Manguinhos 12:205-229.

RENFREW, C. y P. BAHN. 1993. Arqueología. Teorías, Métodos y Prácticas. Akal, Madrid.

SCHEINSOHN, V.; P. MIRANDA; Y. CAMERA; A. GUARIDO; A. LEBENSOHN y A. PÉREZ. 2011. Colecciones ignoradas: Colecciones Arqueológicas en Museos de Ciencias Naturales. El Caso del Museo Argentino de Ciencias Naturales 'Bernardino Rivadavia' (Macn). Actas del II Simposio Colecciones de Museos e Investigación Patrimonio, Diversidad Cultural e Inclusión Social, pp.1-18. CO-
MUIN, Salta.

SOLOMITA BANFI, F. 2006 La colección epistolar de Castellanos: una contribución a la historia de la ciencia. Actas III Jornadas Nacionales Memoria, Espacio e Identidad 2004, editado por B. Dávilo, M. Germain, C. Gotta, A. Manavella y M.L. Múgica. UNR-CONICET, Ediciones digitales Nueva Hélade, Rosario.

SOLOMITA BANFI, F. 2015 Colecciones históricas: aportes para la Historia de la Ciencia. Ponencia presentada en el $\mathrm{V}$ Simposio Nacional e Internacional Teoría y Práctica de la Arqueología Histórica Latinoamericana. Facultad de Humanidades y Artes, Universidad Nacional de Rosario.

VERAS, E. 2010.Historia de Vida: ¿Un método para las ciencias sociales? Cinta moebio 39:142-152.

\section{Otras fuentes consultadas:}

Ley Nacional N9080 año 1913. Ley Nacional 25.743 año 2003. www.censo2010.indec.gov.ar. 
